\title{
Content overview
}

About this second edition, contributors and the author $\quad \mathrm{x}$

Key terms xii

How to use this Field Guide 1

1. Key concepts 4

2. Starting a compliance program 14

3. International data transfers 40

$\begin{array}{ll}\text { 4. Drafting documentation } & 68\end{array}$

5. Maintaining and auditing data privacy compliance programs 110

$\begin{array}{lr}\text { 6. Data privacy A-Z } & 115\end{array}$

$\begin{array}{ll}\text { Checklist } & 201\end{array}$

$\begin{array}{ll}\text { Resources } & 205\end{array}$

$\begin{array}{ll}\text { Abbreviations } & 207\end{array}$

$\begin{array}{ll}\text { Index } & 211\end{array}$ 